\title{
MyBotS Prototype on Social Media Discord with NLP
}

\section{Imam Al Maksur}

\author{
Muhammad Muhajir *
}

\author{
Department of Statistics, Universitas Islam Indonesia, Sleman, Yogyakarta, Indonesia. \\ *Corresponding author:16611064@ students.uii.ac.id, mmuhajir@uii.ac.id* \\ *ORCID ID: https://orcid.org/0000-0003-0512-0899, https://orcid.org/0000-0001-7576-2630*
}

Received 21/12/2020, Accepted 15/3/2021, Published 30/3/2021

This work is licensed under a Creative Commons Attribution 4.0 International License.

\begin{abstract}
:
The continuous growth in technology and technological devices has led to the development of machines to help ease various human-related activities. For instance, irrespective of the importance of information on the Steam platform, buyers or players still get little information related to the application. This is not encouraging despite the importance of information in this current globalization era. Therefore, it is necessary to develop an attractive and interactive application that allows users to ask questions and get answers, such as a chatbot, which can be implemented on Discord social media. Artificial Intelligence is a technique that allows machines to think and be able to make their own decisions. This research showed that the discord chatbot prototype provides various services based on the results of classification testing using the SVM method with three kernels, namely Linear, Polynomial, and RBF. The test data and accuracy values prediction are the largest Liniear Kernel SVM with accuracy and error prediction values of $94 \%$ and $6 \%$.
\end{abstract}

Key words: Artificial Intelligence, Chatbot, Discord, NLP, SVM

\section{Introduction:}

All over the world, technology and technological devices tend to continuously grow with the development of various machines created to help ease various human-related activities. Various studies have shown that buyers or players on the Steam platform still get little information related to games. Irrespective of the importance of information in the current globalization era, loyal Steam players are not provided with the necessary amount. Therefore, based on this problem, it is necessary to develop an application that allows users to ask questions and get adequate replies. For instance, questions regarding game prices, ratings, new game releases dates, etc. The application designed to overcome this issue is the Chatbot, which is implemented on Discord social media and provides adequate assistance to online game players. This device can be installed on Android, Mac, PC, etc. Discord is a new application that is simple, practical, attractive, easy to use and accessible from various gadgets (1). Similar to Whatsapp, Telegram and Skype, this application provides voice chat assistance to gamers and streamers that allows for Voice Over Internet Protocol (VOIP) and messaging among users (2). The application also allows users to contribute through various listening sources. Therefore, by using this application, it is believed that students are likely to shed off the traditional role of being passive receptors (3).

The operative method of the Chabot was carried out in the research design and manufacture of its prototype using an Artificial Intelligence (AI), which is a technology that makes it possible for computers to think and make their own choices. According to Martinez-Plumed et al. (2018), it is not difficult to have computers that are capable of thinking and behaving like humans using artificial intelligence (4). The Chatbot application uses the Natural Language Processing (NLP) programming language which is a field of computer science, AI, and computational linguistics that bridges the gap between clinical human language and computer systems (5).

A 2020 study carried out by Zahour et al. aimed to prepare chatbots based on the theory of John Holland and the RIASEC questionnaire in the field of education and professional guidance, to assess the superiority of the personality styles of undergraduate and postgraduate students seeking to join the labor market (6).

Furthermore, bot architecture research applied to the Discord application was carried out by Septiansyah et al. in 2018 (7). The study was 
conducted by developing a bot that runs on raspberry pi and used as a learning system that is dynamic in performing sensor readings. The bot runs on social media called Discord and enables users to send multiple commands to a server's chat column to ensure it works in accordance with the software algorithm (7). Functional testing is carried out during the Chatbot implementation process, with each tested case able to function properly.

Research on evaluation classification was carried out by Niell et al. in 2018 using the Support Vector Machine method (8). Its purpose was to classify the environment into the categories affected by pesticides. During the research, a simple population-based SVM model was used to estimate the affected area with a classification accuracy of $57 \%$. A variable-based model developed using the results of chemical analysis generated the number of pesticides, toxic units, bees and mammals, field Environmental Impact Quotient, and EIQ field of pesticide detected which provided 100\% classification accuracy (8).

Therefore, based on the description above, this research titled "MyBotS Prototype on Social Media Discord with NLP" was carried out to create a chatbot system capable of interacting with humans and help them in answering questions on the STEAM platform.

\section{Materials and Methods: Artificial intelligence}

Artificial intelligence is a branch of computer science that involves the analysis, design and implementation of smart machines (9). According to Yang (2019), it is used to learn how computers can replicate and execute some of the intellectual functions of human brains (10).

\section{Chatbot}

A chatbot is a program that allows people to have a coherent conversation with machines. The conversation often includes a wide range of vocabulary and conversational topics (11-14). Conversations that occur between computers and humans are a form of response from the program (15)

\section{Natural language processing (NLP)}

Jain et al. (2018) defined Chatbot as a program that allows people to have a coherent conversation with machines (16). This is because the computer learns human language syntax and context, processes it, and gives user output. Artificial Intelligence Markup Language (AIML) is used to model user-chatbot interaction input and output patterns (17).

\section{Artificial intelligence markup language (AIML)}

Artificial Intelligence Markup Language (AIML) aims to facilitate the modeling of communication dialogue (18). AIML defines data objects that are used to model the input and output patterns of a conversation. Furthermore, it represents the knowledge used by Chatbots based on the development of ALICE bot technology (19).

\section{Text mining}

Text mining is mines data typically derived from documents in the form of text (20) and it is shown in Fig. 1. The preprocessing stage is generally needed in text mining on documents (21).

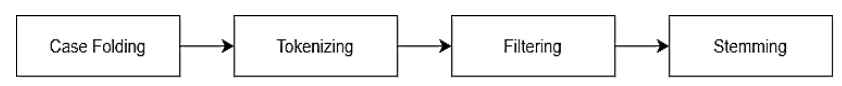

Figure 1. Text Mining Process

Case folding is the process of changing capital letters in a document to lowercase which includes the letters "a" to " $\mathrm{z}$ " and eliminating other characters considered delimiters (22). The case folding process also helps to change the capital letters in the MyBotS dataset to lowercase.

Tokenizing is the process of truncating input strings in text based on the composed words (22). Therefore, this process leads to the generation of words that have been separated in a sentence MyBotS dataset.

Filtering process takes important words or those required for analysis using a stoplist/stopword or wordlist algorithm (22).

Stemming is the process of changing affix into basic words, and this is generally carried out in English text (22). This process is important in MyBots application because it uses English.

\section{Word weighting TF-IDF}

Term frequency-inverse document frequency (TF-IDF) is a numerical statistic that tells users the importance of a word in a list or corpus document in various processes for information recovery and text mining (23-27). It is also used as a weighting factor with different types of algorithms used to construct an automated description (28). Term FrequencyInverse Document (TF-IDF) is the most widely used extractive text description (29).

The type of formula to be used for calculating term frequency (TF) is pure TF (raw TF) because it shows how often a word appears in a particular document (30). Meanwhile, IDF explains the importance of a word in a document which is formulated as follows:

$$
\operatorname{IDF}(A)=\log \frac{D}{d f_{A}}
$$

When the value is similar, zero results for the IDF calculation are obtained. Therefore, a value of $1(+1)$ is added to the IDF formula as follows: 


$$
\begin{aligned}
& I D F(A)=\log \frac{D}{d f_{A}}+1 \\
& W(A)=T F(A) x I D F(A)
\end{aligned}
$$

\section{Support vector machine (SVM)}

Different methods and algorithms of data mining are applied to the development of data classifiers. The most popular tools for data mining include artificial neural networks, decision trees, and SVM algorithm (Support Vector Machine Algorithm) (31). SVM is used to make classification and regression predictions (32).

Suppose there are $n$ variables, and $\left\{\boldsymbol{x} \mid \boldsymbol{x}_{\boldsymbol{i}} \in R n\right.$, $i=1,2, \ldots, m\}$, the input vector is set by building a hyperplane, SVM constructs and a regression model, i.e.

$$
f(x)=\sum_{i=1}^{n}\left(a_{i}^{*}-a_{i}\right) k\left(x_{i}, x\right)+b
$$

where $a i *$ and $a i$ are the Lagrange multipliers, b is offset quantity and the kernel function

$$
\begin{aligned}
& \left\{\left(x_{1}, y_{1}\right),\left(x_{2}, y_{2}\right),\left(x_{3}, y_{3}\right),\left(x_{4}, y_{4}\right) \ldots \ldots \ldots,\left(x_{n}, y_{n}\right)\right\} \\
& k\left(x_{i}, x\right)=\varphi\left(x_{i}\right) \varphi(x)
\end{aligned}
$$

Where $y_{n}=1 /-1$, is a constant which denotes the class of each point $x_{n}$ with $\mathrm{n}=$ number of samples. Each $x_{n}$ is p-dimensional real vector, with scaling used to safeguard variables with greater variety. This training data can be viewed by dividing (or separating) the hyperplane, which requires

$$
w \cdot x+b=0
$$

Where the scalar is $\mathrm{b}$ and the $\mathrm{p}$-dimensional is $\mathrm{w}$, which refers to the perpendicular hyperplane. The margin is increased by adding the offset parameter $b$, with the hyperplane mandated to move through the origin without $b$, thereby restricting the solution. The stages or steps of the classification evaluation analysis in this study are shown in the flowchart in Fig. 2.

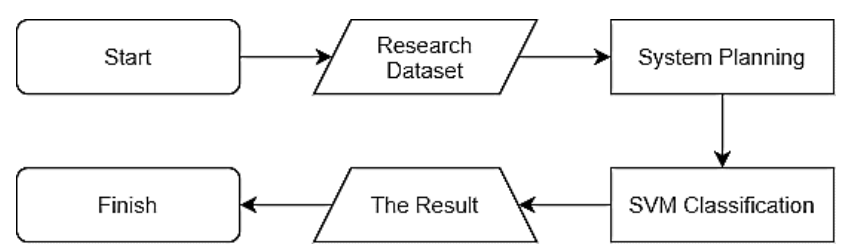

Figure 2. Flowchart of the Classification Evaluation Analysis

\section{Methods:}

\section{The proposed method}

This section introduced an algorithm scheme for designing and making prototypes in the field of computer science, namely AI. The prototypes which were implemented in the form of a chatbot on the Discord social media application used NLP as the newest programming language to make and apply SVM for MyBotS Classification accuracy analysis. The flow process of designing an algorithm and making prototypes of MyBotS is shown in Fig. 3.

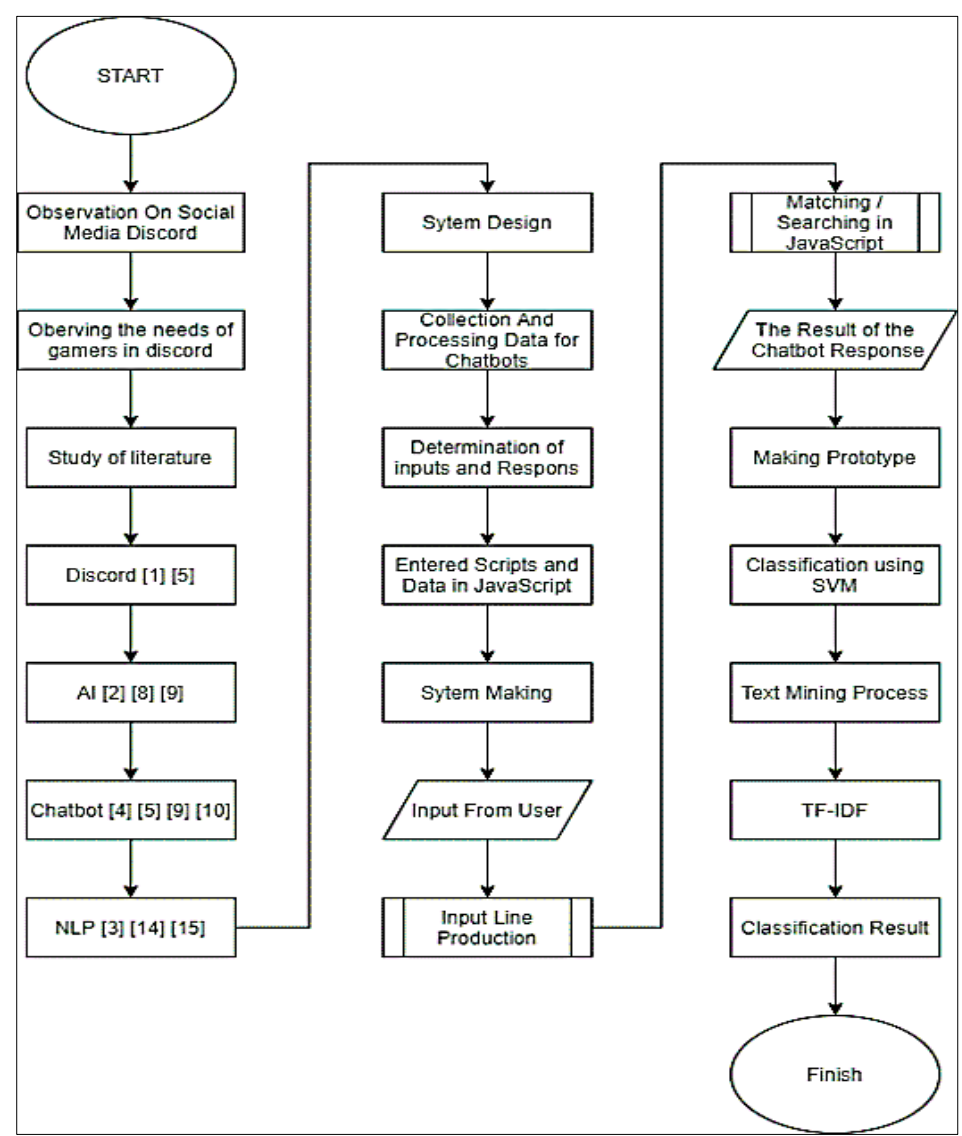

Figure 3. Designing an Algorithm and making prototypes of MyBotS 


\section{Research method:}

Chatbot system was created for game players to obtained relevant information regarding game sales on the Steam platform using the discord social media. It uses NLP as a language-based social media discord program and the STEAM online platform to obtain game sales datasets within 24 hours. Therefore, based on the objectives of the system, the following features need to be included in the Chatbot:

a. Functional requirements:1) Steam Store information, 2) Steam Event, 3) Clan Event, 4) Music Bot, and 5) a relaxing game features of Ball8 Game Bot.

b. Non-functional requirements: 1) This chatbot system can be accessed on Discord social media, and 2) has a user-friendly interface.

c. Software requirements: 1) Visual Studio Code, 2) Sniping Tools, 3) Java Script nodes, 4) Discord, 4) Steam, 6) Ffmpeg, and 7) Browser

d. Hardware requirements: 1) CPU: Intel ${ }^{\circledR}$ Core тм i5-7300HQ CPU @ 2.50GHz, 2) GPU: NVIDIA GeForce GTX 1050 4GB, 3) RAM: Team T-Force Vulcan SODIMM DDR4 16Gb, 4) Hard drive: $2 \mathrm{~TB}$, and 5) Laptop: LEGION Y520

In designing the system, a database is needed to store goods and user. The database used to carry out this research is json which saves directly to a private folder.

The steps or stages in this research are shown in the flowchart in Fig. 4.

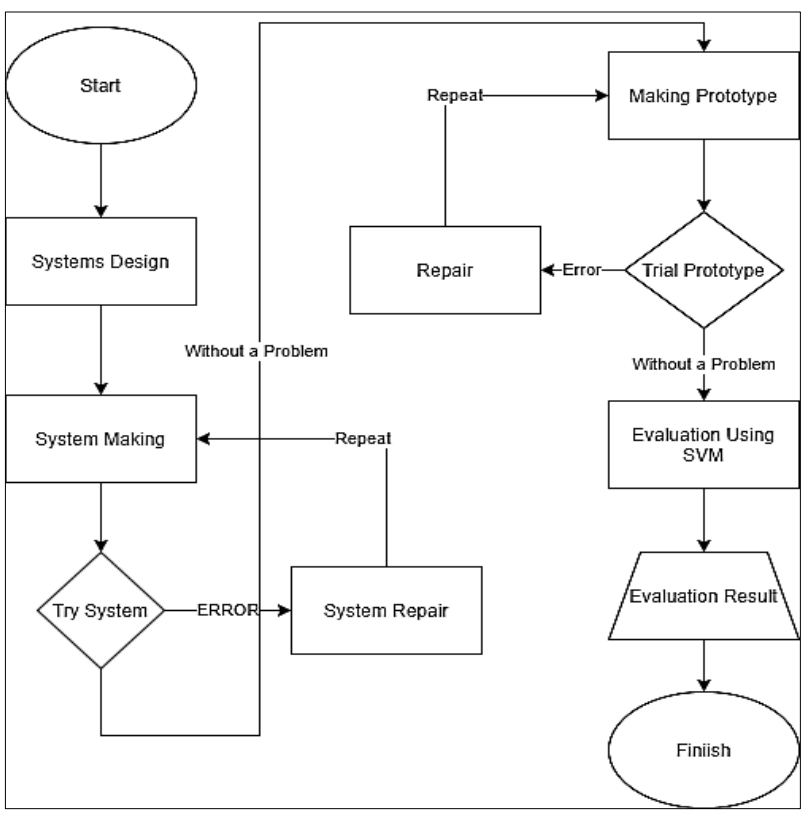

Figure 4. Research Flowchart

\section{Results and Analysis: \\ Problem and implementation of the Chatbot System}

Natural Language Processing (NLP) is a method used to implement Chatbot in solving STEAM platform information problems. Chatbot application also needs information retrieval (IR) to obtain information when questioned. This chatbot system was designed using the graph master pattern matching method, which serves as an answer search algorithm. In the Analysis phase, the Chatbot built provides information regarding STEAM STORE to users on Discord social media. The context diagram comprising of the highest DFD level representing the system input or output provides a summary of the entire system. Chatbot's background diagram is shown in Fig. 5.

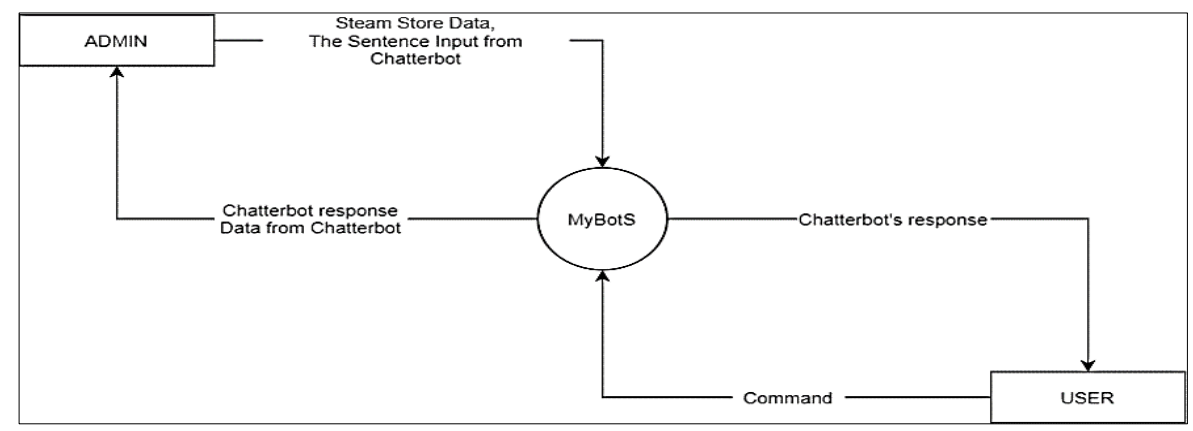

Figure 5. Context Diagram Chatbot

Figure 5, shows that the context diagram has two entity, namely admin and users. Admin needs to first log into the developer Discord system in order to access the Chatbot script. They are tasked with managing data, maintaining and repairing Chatbot. Admin can also manage data script, and responsible for various activities, such as Create, Read, update, delete (CRUD) and search. They have the ability to carry out a chatbot test on MyBotS test channel, which is one of the channels that can only be accessed by the Admin or Owner. Meanwhile, users of Discord can only have a conversation or 
chat by entering sentences or questions on the features of the MyBotS Chatbot.

Natural Language Processing

The NLP system consists of 3 parts, namely input, knowledge base and output. After the Chatbot is invited into the discord server, the user greets it with the word, hello to start a conversation. This is followed by a reply prompting users to input further details to be processed, which is searched to determine matching knowledge base on what is contained in the chatbot script. When the appropriate data is found, bot proceeds to provide appropriate answers to the user input. After the answer is found, it is displayed on the output channel. The flow diagram of the chatbot system is shown in Fig. 6.

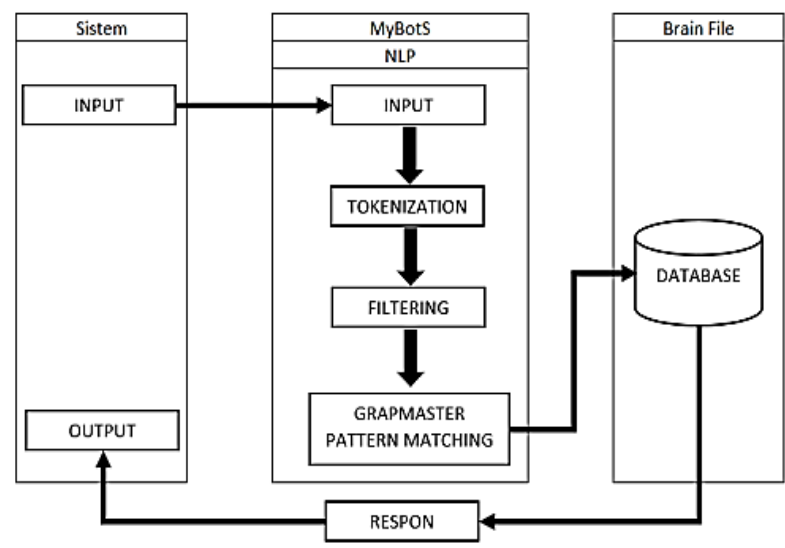

Figure 6. Flow of the chatbot system

\section{Knowledge Base Chatbot}

In the chatbot system analysis is given, which is used as a knowledge base, which is tabulated, as shown in Table 1.

Table 1. Chatbot knowledge base

\begin{tabular}{|c|c|c|}
\hline No & Pattern & Template \\
\hline 1 & $\begin{array}{l}\text { switch }(\operatorname{args}[0])\{ \\
\text { case "hallo": } \\
\text { break; }\}\end{array}$ & 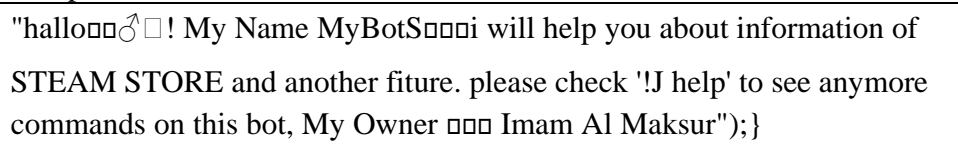 \\
\hline 2 & $(\mathrm{msg} 01$.content $=!$ JSteam Store' $)\}$ & $\begin{array}{l}\text { Steam Store, Top Seller Games, the best collection of game sales on the } \\
\text { Steam Platform. }\end{array}$ \\
\hline 3 & $\begin{array}{l}\text { ('message', msg }=>\{(\text { msg.content } \\
\text { !J Steam Game "nama game") }\end{array}$ & $\begin{array}{l}\text { Game name, game description, current game price, Publisher, Developer, } \\
\text { Genre, Release Date, and user review }\end{array}$ \\
\hline 4 & $\begin{array}{l}\text { ("message", asyncmsg => } \\
\{\text { (msg.content }===! \mathrm{J} \text { Event })\end{array}$ & Information related to the event that will be held next \\
\hline 5 & $\begin{array}{l}\text { ("message", asyncmsg }=> \\
\{\text { (msg.content }===! \mathrm{J} \text { Date) }\end{array}$ & To determine the date and time of upcoming events. \\
\hline 6 & $\begin{array}{l}\text { case 'play': } \\
\text { function play(connection, msg)\{ } \\
\text { \{connection.disconnect();\} }\end{array}$ & $\begin{array}{l}\text { you need to provide a link | you must be in the channel to use the bot! } \\
\text { MyBotS akan memainkan musik req di Voice Channels }\end{array}$ \\
\hline 7 & $\begin{array}{l}\text { case 'skip': } \\
\text { var server = servers[msg.guild.id]; } \\
\text { server.dispatcher.end(); } \\
\text { break; }\end{array}$ & skip the song! \\
\hline 8 & $\begin{array}{l}\text { case 'stop': } \\
\text { var server = servers[msg.guild.id]; } \\
\text { (msg.guild.voiceConnection) }\{\text { break; }\end{array}$ & End the queue leaving the voice channel! \\
\hline 9 & $\begin{array}{l}\text { ("message", msg => }\{\text { constmsgToLower } \\
\text { = msg.content.toLowerCase }() \\
\text { constgameArray = } \\
\text { ["rock", "paper", "scissors"]; }\end{array}$ & $\begin{array}{l}\text { "It's a draw! ם", "The computer wins! ם", "You win! ם"; } \\
\text { "You've chosen rock!", "You've chosen paper!", "You've chosen scissors!"; } \\
\text { Pc has chosen: }\end{array}$ \\
\hline
\end{tabular}

\section{Chatbot Prototype Response}

The chatbot program that has been built produces a simple response on information about the Steam Store, Steam Game, Event, Music bot and paper rock scissors game, as shown in Table 2. 
Table 2. Chatbot Prototype Reponse

Opening

List command MyBotS

Steam Store

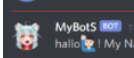

(.) Owner Today at 12:10 PM

MyBotS EOT Today at 12:10 PM

\begin{tabular}{|c|}
\hline F |Command List Botץ I \\
\hline $\begin{array}{l}\text { Steam Store } 5 \text { to } \\
1 \text { y Steam Store } \\
2 \text { U Steam Game INama Game }\end{array}$ \\
\hline 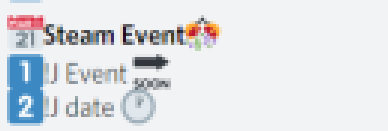 \\
\hline 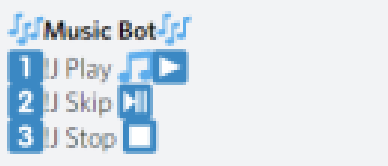 \\
\hline 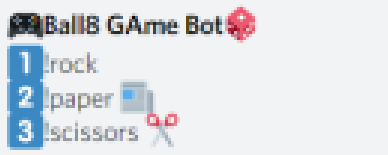 \\
\hline
\end{tabular}

Ownes Trow in wam

IUSteam Store

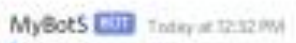

- קsteamstoke

YTOP SELLERS GAMEY

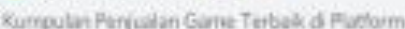
Strath

Yotinam

T) Nonster Honter Worid

2 Datise 2

3 Jonclinen Ruritew sioet Swess

4 Tie Ebar scrolis: Oreme

5 WABSTAME

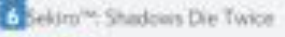

Yoold Y

1 peidentitel 2

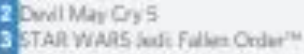

4 Teasbronotistit

5. Wha. The Master Chiet Colloction

6 occent coneur

Ysitwer?

1 yed Oend Redervonon 2

2 plans 260

3 stallers

4 Pinhty Orishol $\sin 2$-Dethative Edtion

6. ins Tnuas Semidar? 
Steam Game

Steam Event

Event Date

Music Bot
Owner Taden an rzarim

I) Steam Game Manster Hunfer

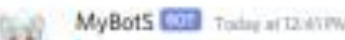

Monster Hunter: Worke

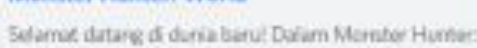

Werle versi terbaru delam seri itic Anda dape

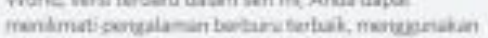

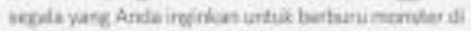

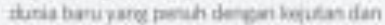

tepmitionan

Harga $\$$ PUBusher 9 develoeer 9

PA 221099 CAACOMCO CAACOMCOIC

Pa. 221099

Harion homd

uid bi

Pa. 336959 )

GENGE - PELEASEDATE USER REVIEWS

Action Open D. Wi

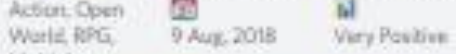

Multiving

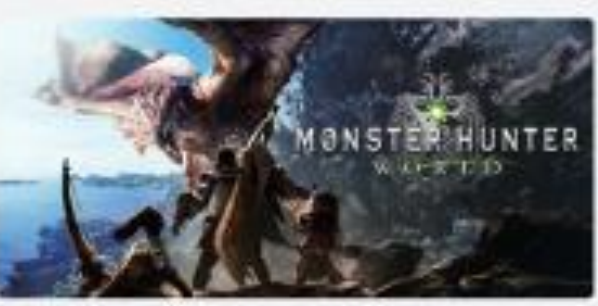

Owner To

Owner Tovent

MyBots E⿱一廾丿⿸厂二

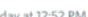

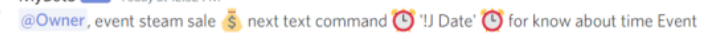

.. Owner Today at 12:57 PM

IJ Date

MyBotS EOT Today at 12:57 PM

@ Owner, Next Steam event date is: 12/01/20 00:00 GMT

The event begins in: $3275 \mathrm{~h} 3 \mathrm{~m}$

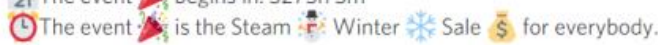

S.8.

Jabberworky Yesterday at 10:22 AM

!Jplay https://www.youtube.com/watch?v=2aZKU1AxLYQ

MyBotS Bor Yesterday at 10:22 AM

you must be in channel to play the bot!

VOICE CHANNELS

D General

Jabberworky

MyBots 


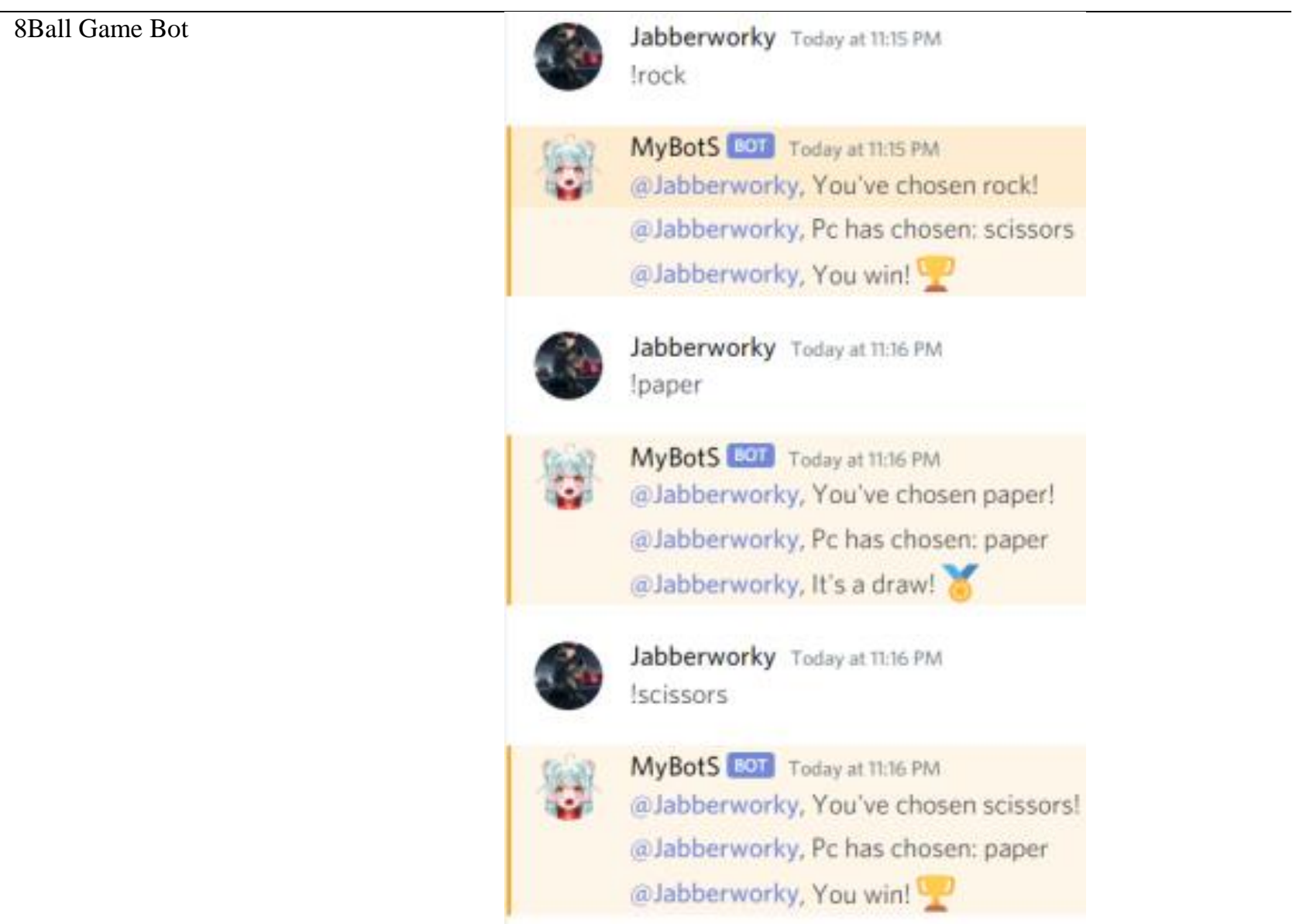

\section{Support Vector Machine}

Prior to the classification process, data is first separated into training and testing. The training and testing data used were $80 \%$ and $20 \%$ of total data, i.e. 67 and 17, which were classified using the Vector Machine kernel algorithm. Kernels are Linear, Poly and RBF, therefore, before classifying the data, TF-IDF words were preprocessed and weighed. The classification process involves training data to construct a model, which is used for testing. Classification of Support Vector Machine uses 3 kernels, namely Linear, Poly, and RBF. The results of the SVM classification comparison are summarized in Table 3.

Table 3. Summary of SVM classification results with the three kernels

\begin{tabular}{cccc}
\hline Kernel & Accuracy & Error & Description \\
\hline Linear & $100 \%$ & $0 \%$ & Training \\
Linear & $94 \%$ & $6 \%$ & Testing \\
Polynomial & $86 \%$ & $14 \%$ & Training \\
Polynomial & $64.7 \%$ & $35.3 \%$ & Testing \\
RBF & $97 \%$ & $3 \%$ & Training \\
RBF & $82.3 \%$ & $17.7 \%$ & Testing \\
\hline
\end{tabular}

Table 3 shows that comparing SVM classifications using three different kernels shows that the Linear kernel has a higher accuracy of $100 \%$ and $94 \%$ for training and testing data. Furthermore, to ensure that the Linear kernel has better accuracy than the Polynomial and RBF kernels for this study Discord-based social media chat Discord was developed by providing various service categories, such as Steam Shop, Steam Case, Music Bot and Ball8 Game both categories.

\section{Predict categories on new question dataset}

After determining the results of the SVM classification model with a linear kernel, the model is evaluated using new question data, which is not included in the training data. 
"1) !J Game Steam Fall Guys?" - Prediksi: 'Steam Store'

"2) IJ Game terbaru Steam tahun 2020?"

- Prediksi: 'Steam Store'

"3) ! J Steam Store 2021?"

- Prediksi: 'steam Store'
"4) IJ Game Steam GTA 6 ?"

- Prediksi: 'Steam Store'

"5) !J Game Steam Action ?" - Prediksi: 'steam Store'

"6) ! J Play Music Syar'i?" - Prediksi: 'Music Bot'
"7) !J Event of Years?" - Prediksi: 'Steam Event'

"8) !J Date Years Event?" - Prediksi: 'Steam Event'

"9) Irock pilihanku ?" - Prediksi: 'Game Bot'

\section{Figure 7. Prediction Result of the New Question}

Figure 7 shows that the evaluation of prediction is in a very good category with 9 more questions that are not misclassified. However, despite this classification, the Chatbot still needs to be trained.

\section{Descriptive Statistics}

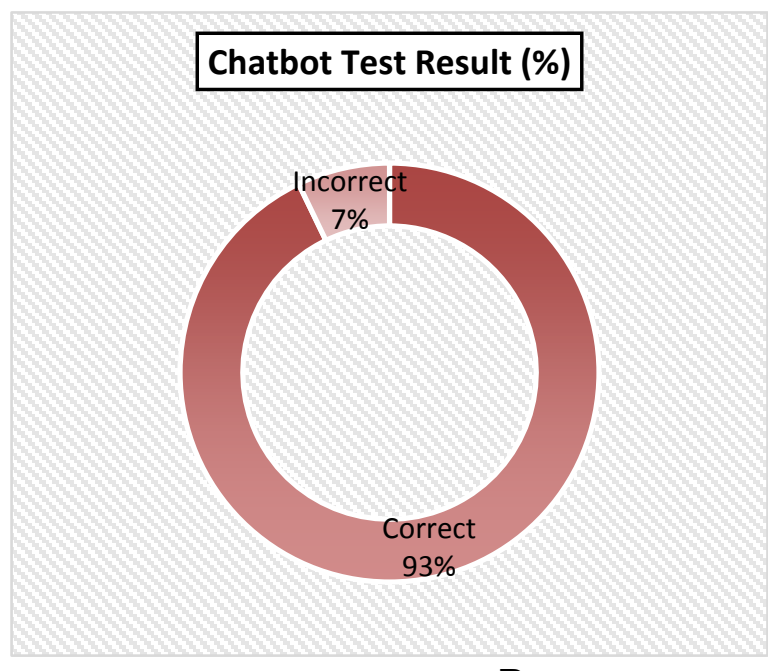

B

Figure 8. (a) Percentage of user questions (b)Percentage of Chatbot Test Results

Figure $8 \mathrm{a}$ shows that the most frequently asked questions are in the Steam Store category, with a percentage of $68 \%$. The Music bot category follows this at $18 \%$. Meanwhile, the least asked questions were in the Game Bot and Steam Event category with a percentage of $7 \%$.

Overall, 84 questions were asked by Discord users. Figure $8 \mathrm{~b}$ showed that the Chatbot answered the questions asked by the user correctly at a percentage of $93 \%$ while the wrong answers were $7 \%$.

\section{Conclusion:}

In conclusion, discord-based social media chat has been built by providing various service categories, such as Steam Store, Steam Event, Music bot and Ball8 Game bot. Furthermore, based on the results of the Support Vector Machine (SVM) classification analysis with three kernels, namely Linear, Polynomial, and RBF kernels with testing data, the accuracy value of the prediction category is greatest using SVM with a Linear kernel, of $94 \%$ and prediction error of $6 \%$. The chatbot program system provides answer responses with an accuracy value of $100 \%$ and an error of $0 \%$ from 10 new questions.

\section{Acknowledgment:}

The authors are grateful to the Department of the Statistics Islamic University of Indonesia for their support throughout the research process.

\section{Authors' declaration:}

- Conflicts of Interest: None.

- We hereby confirm that all the Figures and Tables in the manuscript are mine ours. Besides, the Figures and images, which are not mine ours, have been given the permission for republication attached with the manuscript.

- Ethical Clearance: The project was approved by the local ethical committee in Universitas Islam Indonesia.

\section{References:}

1. Raihan JP, Putri YR. Communication Pattern Discord Group PUBG.INDO.FUN Through Application Discord. e-Proceeding Manag. 2018;2(3):4161-9.

2. Lacher L, Biehl C. Using Discord to Understand and Moderate Collaboration and Teamwork. Proc 49th 
ACM Tech Symp Comput Sci Educ. 2018;11071107.

3. Wulanjani AN. Discord Application:Turning a Voice Chat Application for Gamers into a Virtual Listening Class. 2nd English Lang Lit Int Conf. 2018;2:115-9.

4. Martínez-Plumed F, Loe BS, Flach P, Eéigeartaigh S, Vold K, Hernández-Orallo J. The facets of artificial intelligence: A framework to track the evolution of AI. IJCAI Int Jt Conf Artif Intell. 2018;2018July:5180-7.

5. Juhn Y, Liu H. Artificial intelligence approaches using natural language processing to advance EHRbased clinical research. J Allergy Clin Immunol [Internet]. 2020;145(2):463-9. Available from: https://doi.org/10.1016/j.jaci.2019.12.897

6. Zahour O, Benlahmar EH, Eddaoui A, Ouchra H, Hourrane O. A system for educational and vocational guidance in Morocco: Chatbot e-orientation. Procedia Comput Sci [Internet]. 2020;175:554-9. Available from: https://doi.org/10.1016/j.procs.2020.07.079

7. Septiansyah R, Akbar SR, Maulana R. Perancangan Bot Pada Discord Untuk Pembacaan Sensor Di Raspberry Pi Dengan Sistem Learning Yang Dinamis. J Pengemb Teknol Inf dan Ilmu Komput Univ Brawijaya. 2018;2(10):4202-12.

8. Niell S, Jesús F, Díaz R, Mendoza Y, Notte G, Santos $\mathrm{E}$, et al. Beehives biomonitor pesticides in agroecosystems: Simple chemical and biological indicators evaluation using Support Vector Machines (SVM). Ecol Indic [Internet]. 2018;91(May 2017):149-54. Available from: https://doi.org/10.1016/j.ecolind.2018.03.028

9. Zhang $H$. Analysis of artificial Intelligence Technology in Electric Automation Control. J Phys Conf Ser. 2019;1345(5).

10. Yang LB. Application of artificial intelligence in electrical automation control. Procedia Comput Sci [Internet]. 2020;166:292-5. Available from: https://doi.org/10.1016/j.procs.2020.02.097

11. Heller B, Procter M, Mah D. Freudbot: An investigation of chatbot technology in distance education. Proc World Conf Educ Multimedia, Hypermedia Telecommun [Internet]. 2005;(March 2016):3913-8. Available from: http://www.editlib.org/index.cfm?fuseaction=Reader. ViewFullText\&paper_id=20691

12. Beaudry J, Consigli A, Clark C, Robinson KJ. Getting ready for adult healthcare: Designing a chatbot to coach adolescents with special health needs through the transitions of care. J Pediatr Nurs [Internet]. 2019;49:85-91. Available from: https://doi.org/10.1016/j.pedn.2019.09.004

13. Sutoyo R, Chowanda A, Kurniati A, Wongso R. Designing an emotionally realistic chatbot framework to enhance its believability with AIML and information states. Procedia Comput Sci [Internet]. 2019;157:621-8. Available from: https://doi.org/10.1016/j.procs.2019.08.226

14. Dhyani M, Kumar R. An intelligent Chatbot using deep learning with Bidirectional RNN and attention model. Mater Today Proc [Internet]. 2020;(xxxx). Available

from: https://doi.org/10.1016/j.matpr.2020.05.450

15. Setiaji B, Wibowo FW. Chatbot Using a Knowledge in Database: Human-to-Machine Conversation Modeling. Proc - Int Conf Intell Syst Model Simulation, ISMS. 2016;0:72-7.

16. Jain A, Kulkarni G, Shah V. Natural Language Processing. Int J Comput Sci Eng. 2018;6(1):161-7.

17. Garousi V, Bauer S, Felderer M. NLP-assisted software testing: A systematic mapping of the literature. Inf Softw Technol. 2020;126(March).

18. Bruno Marietto M das G, Aguiar RV, Barbosa G de O, Botelho WT, Pimentel E, Franca R dos S, et al. Artificial Intelligence Markup Language: A Brief Tutorial. Int J Comput Sci Eng Surv. 2013;4(3):1-20.

19. Abdul-Kader SA, Woods JC. Survey on Chatbot Design Techniques in Speech Conversation Systems. Int J Adv Comput Sci Appl. 2015;6(7):72-80.

20. Miner G, Elder J, Hill T, Delen D. A Fast, Practical Text Mining and Statistical Analysis for NonStructured Text Data Applications. Acad Press Waltham, MA. 2012;

21. Mooney RJ. Machine Learning Text Categorization. Mach Learn Text Categ. 2006;1-6.

22. Engelhart MD, Aiken LR. The text mining handbook: Advanced approaches in analyzing unstructured data. Educ Psychol Meas. 1975;35(1):199-199.

23. Cummins R, O'Riordan C. Evolved term-weighting schemes in information retrieval: An analysis of the solution space. Artif Intell Rev. 2006;26(1-2):35-47.

24. Soucy P, Mineau GW. Beyond TFIDF weighting for text categorization in the vector space model. IJCAI Int Jt Conf Artif Intell. 2005;1130-5.

25. Cummins R. The Evolution and Analysis of TermWeighting Schemes in Information Retrieval. Analysis. 2008;201.

26. Kumari M, Jain A, Bhatia A. Synonyms Based Term Weighting Scheme: An Extension to TF.IDF. Procedia Comput Sci [Internet]. 2016;89:555-61. Available http://dx.doi.org/10.1016/j.procs.2016.06.093

27. Salton G, Buckley C. TERM-WEIGHTING APPROACHES IN AUTOMATIC TEXT RETRIEVAL GERARD. Inf Process Manag. 1988;24(5):513-23.

28. Munot N, Govilkar SS. Comparative Study of Text Summarization Methods. Int J Comput Appl. 2014;102(12):33-7.

29. Christian H, Agus MP, Suhartono D. Single Document Automatic Text Summarization using Term Frequency-Inverse Document Frequency (TFIDF). ComTech Comput Math Eng Appl. 2016;7(4):285.

30. Susilowati E, Sabariah MK, Gozali AA. Implementation Support Vector Machine Method for Traffic Jam Classification on Twitter. e-Proceeding Eng. 2015;2(1):1478-84.

31. Demidova LA, Klyueva IA, Pylkin AN. Hybrid approach to improving the results of the SVM classification using the random forest algorithm. Procedia Comput Sci [Internet]. 2019;150:455-61. Available from:

https://doi.org/10.1016/j.procs.2019.02.077 


\title{
النموذج المبئي ل MyBotS على وسائل التواصل الاجتماعي Discord مع البرمجة اللغوية العصبية
}

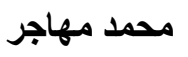

\author{
امام المكسور
}

قسم الإحصاء ، الجامعة الإسلامية إندونيسيا ، سليمان ، يوجياكارتا ، إندونيسيا

أدى النمو المستمر في التكنولوجيا والأجهزة التكنولوجية إلى تطوير الآلات للمساعدة في تسهيل الأنشطة المختلفة المتعلقة بالبشر.

الخلاصة:

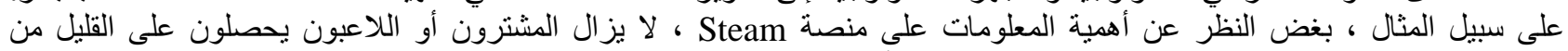

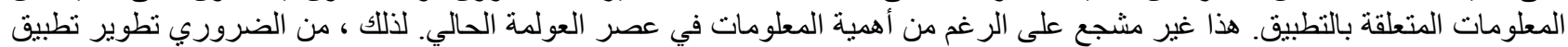

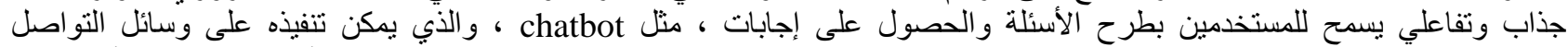

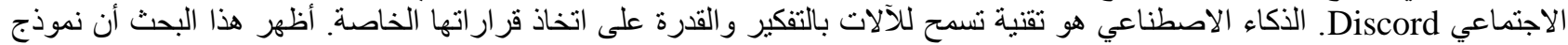

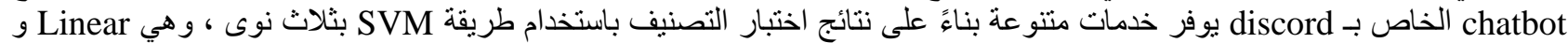

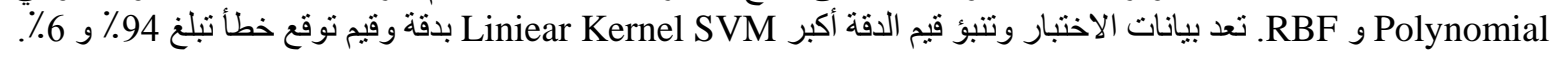

الكلمات المفتاحية: الذكاء الاصطناعي ، روبوت الدردشة ، Discord ، البرمجة اللغوية العصبية ، DVM 